\title{
A Study on the Prevalence of Bovine Mastitis and Isolation of Major Pathogens Associated with it in and around Wolaita Sodo, Southern Ethiopia
}

\author{
Esayas Balcha Madalcho \\ Jig-Jiga University, College of Veterinary Medicine, Jig-Jiga, Ethiopia
}

*Corresponding Author: Esayas Balcha Madalcho, Jig-Jiga University, College of Veterinary Medicine, Jig-Jiga, Ethiopia

\begin{abstract}
A cross sectional study to determine the prevalence of bovine mastitis in Jersey, Indigenous and Holstein Friesian was carried out from November 2011 to April 2012 in and around Wolaita Sodo town. This study based its operation center at Sodo Regional Laboratory, department of bacteriology.

A total of 349 dairy milking cows were studied 62 Jersey, 237 Indigenous Zebu and 50 Holstein by using California Mastitis Test (CMT). Prevalence of bovine mastitis at cow level was 35.5\% (124/349), out of which $5.4 \%$ (19/349) and 30.1\%) 105/349) were clinical and sub clinical, respectively. The quarter level prevalence was 25.7\% (359/1396); from this the clinical and sub clinical forms were 4.4\% (62/1396) and $21.3 \%$ (297/1396), respectively. The prevalence of blind quarter in the current study was 3.8\% (53/1396) while the active clinical form of quarter was $4.4 \%$ (62/1396). Samples from all 62 active clinical cases and 96.6\% (287/297) of the California Mastitis Taste (CMT) - positive sub clinical quarters were found to be culture positive. From CMT - positive sub clinical quarters, 3.4\% (10/297) were found to be culture negative. From 349 culture positive samples, a total of 113 bacteria were isolated, the most prevalent being $S$. aurues (53.9\%). Other bacterial isolates included Streptococcus species (39.8\%), E. coli (2.7\%), and Corynebacterium species (1.8\%) and Salmonella (1.8\%). Risk factors analysis revealed that the prevalence significantly differed with parity $(p<0.05)$ and insignificantly differed with the other risk factors. This study revealed high prevalence of mastitis thus based on this some recommendations was forwarded aiming at reducing the prevalence of the disease.
\end{abstract}

Keywords: Bovine mastitis, Holstein, Jersey, major pathogens, prevalence, Wolaita Sodo, Zebu

List of Abbreviations: CMT: California Mastitis Test, M.A.S.L: meter above sea level, SCC: Somatic Cell Count

\section{INTRODUCTION}

Bovine mastitis is the most common disease in adult dairy cows, accounting for about $38 \%$ of morbidity (Smith, 1996). Regardless of the cases, mastitis is an inflammation of parenchyma of mammary gland. It results from infection with microorganisms, injuries and chemical irritants (Pyorola, 2003). Depending on the cause, bovine mastitis can be classified as contagious mastitis, environmental mastitis, mastitis due to teat skin opportunistic pathogens and summer mastitis (Smith et al., 1993). About 140 microbial species, sub species and serovars have been isolated from the bovine mammary gland through microbiological techniques (Quinn et al., 2002).

Contagious mastitis is intramammary infection by pathogens that lives and multiplies principally in cow udder. Spread is common from cow to cow through milkers hand, clothes and teat cup. These microorganisms include Staphylococcus species, Corynebacterium bovis, Mycoplasma species (Lowerence and Fox, 1993). The other microorganisms included are Streptococcus species (Quinn et al., 2002).

Environmental mastitis is caused by pathogens that are found from the environment, feaces, bedding, water and flies and multiply in udder. In contrast, unlike contagious mastitis exposure of uninfected quarter to environmental pathogens occur at any time during the life of the cow (Faul and Hughe, 1995; Smith et al., 1985). The causes of environmental mastitis includes Coliform (E.coli,Klebsiella species and Entrobacteria), Serratia, Pseudomonas, Proteus species and environmental Streptococcus species (Streptococcus uberis) (Smith and Hoghe; 1993). 
Summer mastitis is dual infection by Corynebacterium pyogenus and anaerobes of Peptostreptococcus indolicus that occur in heifers and dry cow in pasture in summer month. Summer mastitis is fly born common in wet weather and creates a systemic reaction and loss of function of quarter. The secretion of this foul smells attributes to the activities of anaerobes (Radostits et al., 2000). Some of microorganisms which are responsible for sporadic occurrence of mastitis includes: Salmonella species, Mycoplasma species, Bacillus cereus, and Clostridium perferingens (Tolle, 1984).

Three major factors are involved for the occurrence of the disease these are: the microorganisms as a causative agent, the cow as the host and the environment which can influence both cow and microorganisms (Radostits et al., 2000).

Although mastitis occurs sporadically in all species, it has major economic importance in dairy cattle and may be one of the most costly diseases in dairy herds. Mastitis results in economic loss for producers by increasing the cost of production and by decreasing productivity. The premature culling of potentially profitable cows because of chronic mastitis is also significant loss. There are additional costs associated with antimicrobial residues in milk from treated cow, low nutritional quality of milk, degrading of milk quality and supply due to high bacteria load, and additional cost incurred for manufacturing of dairy products from low grade milk. Milk with high bacterial load causes interference with manufacturing process (Risco et al., 1999).

With mastitis, there is a danger that the bacterial contamination of milk from affected cows may render it unsuitable for human consumption by causing food poisoning and infection. Raw (unpasteurized) milk can be a source of food borne pathogens. For instance, sampling bulk tank raw milk in Ontario revealed the presence of Listeria monocytogens, Salmonella species, Campylobacter species, or verocytoxigenic E.coli in $2.5 \%, 0.2 \%, 0.5 \%$, and $0.9 \%$ milk samples respectively (Steele $e t$ al., 1997). Principles of control include elimination of the existing infection, prevent new infection and monitor udder health status. The various components of mastitis control program include: using proper milking management method; proper installation, functioning and maintaining of milking equipment; dry cow management, appropriate therapy of mastitis during lactation, culling of chronically infected cows, maintaining appropriate environment, good record keeping, monitoring udder health status, periodic review of the udder health management program and setting goals for udder health status (Hillerton, 1996).

In Ethiopia, even though the disease has been studied, it was not systematic. Hundera et al. (2005) studied the prevalence of mastitis and associated economic loss and they reported a prevalence rate of $16.11 \%$ clinical and $36.67 \%$ subclinical mastitis. The prevalence of clinical and subclinical mastitis in selected areas of Southern Ethiopia ranges from 1.2 to $21.5 \%$ and 19 to $46.6 \%$, respectively (Kerro and Tareke, 2003). An old study by Demelash (1994) in Wolaita Sodo had indicated that the prevalence of bovine mastitis in indigenous Zebu cattle and exotic Jersey breeds was $33.0 \%$. Another study (Demelash et al., 2005) in the same area had reported the occurrence of bovine mastitis with a prevalence rate of $34.9 \%$, which is higher than the former. However, there is lack of information about the current status of bovine mastitis in Wolaita Sodo; and the major pathogens associated with the occurrence of mastitis are not well known. Thus, beginning from November 2011 to April 2012, this study was carried out with the following objectives:

General Objectives:

$>$ To determine the prevalence of bovine mastitis and isolate the major pathogens associated with it in and around Wolaita Sodo town.

Specific Objectives:

To determine the prevalence of disease in and around Wolaita Sodo town;

To identify the potential risk factors associated with the disease of mastitis in bovine and

$>$ To identify the major pathogens responsible for bovine mastitis in the study area

\section{Materials ANd Methods}

\subsection{Description of Study Areas and Population}

\subsubsection{Study Areas}

The current study was carried out in Wolaita Sodo town and its surrounding from November, 2011 to April 2012. Wolaita Sodo town is found about $330 \mathrm{~km}$ away from Addis Ababa. It is located at 
alatitude of $8^{0} 50^{\prime} \mathrm{N}$ and longitude of $37^{0} 45^{\prime} \mathrm{E}$. The area covers about 63,282 hectares of land with the total population 285,598 . Topographically, the area is marked by flat $(40 \%)$, valley $(25 \%)$ and mountain $(35 \%)$. The altitude ranges from 1700 to 2950 meter above sea level (m.a.s.l). The area experiences a mean annual temperature of about $24^{\circ} \mathrm{c}$. The mean maximum temperature is $26.2^{\circ} \mathrm{c}$ and the average monthly minimum temperature is about $11.4^{\circ} \mathrm{c}$. The rainfall regime over much of the area is typically bimodal with the long rainy season extending from June to September and a small rainy season occurring from February to April. The annual rainfall of the area ranges from 450 to 1446 millimeter (mm) (Wolaita Sodo meteorology station record, 2011).

The prevailing agricultural system in the area is mixed farming with crop and livestock production. The subsistence needs of rising human population are resulting in the progressive extension of the area under cultivation and subsequent limitation of grazing lands. The livestock population in the area is 128,919 cattle, 4606 goat, 24585 sheep, 3872 donkey, 121 horse, 131 mule and 54,587 poultry (Wolaita Zone Animal Health and Resource Management Office, 2011)

\subsubsection{Study Animals/ Population}

The study population is lactating cows found in the study area. The study included local Zebu, a Holstein Friesian, and pure Jersey breed cows. The indigenous Zebu breed cows found in the area are managed under traditional extensive system by peasants as a source of milk, meat and drought power and as a means of generating income. Usually they are kept on pasture grasses, but occasionally fed withfalse banana as a cut and carry system. The Holstein Fresian breeds are managed under semiintensive by small holders for the purpose of milk production. These animals feed on the field and sometimesupplemented with concentrates and hay. Their management systems are somewhat better than the Zebu cattle but less better than the Jersey breeds in the dairy farm of WolaitaSodo town.

The dairy herd of Jersey breeds at WolaitaSodo town farm is managed by trained personnel. Cows are kept in stalls built with concrete flooring and are allowed to grazefor five hours in a day. Additionally theywill be supplemented with green feed as a cut and carry system, fodders and concentrates. Manure is removed daily and frequently whenever uncleanness exists. However, since the floor is not maintained for a long period of time, there are pot holes on the surfaces that lodge moisture. Premilking preparations includes washing of udder by flushing with warm water and drying the udder by wiping with towels. But the towels are not provided for individual cows. Calves are reared in individual pens isolated from their dams.

\subsubsection{Study Design}

A cross-sectional study was conducted from November 2011 up to April 2012 to determine the prevalence of Bovine mastitis in the study area, and to isolate and identify the major pathogens associated with the disease.

\subsubsection{Sampling Method and Sample Size Determination}

Systematic random sampling method was employed to select the study animals. The sample size was determined by using the formula given by Thus field (2005) for simple random sampling method.

$n=\frac{1.96^{2} \times \operatorname{Pexp}(1-\text { Pexp })}{d^{2}}$

Where: $\mathrm{n}=$ sample size

$$
\begin{aligned}
& \text { Pexp }=\text { expected prevalence } \\
& d=\text { desired level of precision }
\end{aligned}
$$

For the calculation of the sample size an expected prevalence of $34.9 \%$ was used from previous study in similar study area (Demelash et al, 2005). The precision level was decided to be 5\% at a confidence interval of $95 \%$. Accordingly, a total of 349 lactating cows were included in the current study. To attain this number, 42 cows from Wolaita Sodo dairy farm (Jersey breeds), 40 cows from Sodo veterinary clinic, 100 cows from urban dairy holders and 167 cows from peri-urban areas were selected randomly. 


\subsection{Study Methodology}

\subsubsection{Data Collection and Detection of Mastitis}

All the necessary information regarding study sites, animal identification, breed, parity number, calving date hence lactation period and stage, clinical examination results of the udder and teat as clinical and sub-clinical case were recorded on the sample collection format.

Although mastitis in an individual cow may be obvious, it is more often a sub-clinical disease (Radostits et al., 1994). Therefore, tests for detection of changes in the udder or the milk caused by mastitis are necessary. Clinical mastitis was detected through physical examination of the udder and teat. All udder quarters of the sampled cows were observed for presence of any palpable and visible abnormalities of the udder and teat, such as swelling, atrophy, lesions, blindness of teat and the nature and appearance of milk secretions.

The other forms of mastitis the sub clinical form of mastitis which is an inflammation of mammary gland in the absence of visible abnormality of milk or it is the presence of pathogenic microorganisms in the milk and somatic cell count (SCC) above acceptable level of cells /ml of milk. It can only be diagnosed with the screening test or laboratory procedure (Radostits et al., 1994).

\subsubsection{Milk Sampling Procedures}

Milk sampling were performed aseptically after the udder had been washed clean and dried with clean towel and disinfected using alcohol swabs. Handmade ready for sampling was also washed with detergent (soap) and disinfected. The external sphincter of the teats was extruded by pressure to ensure that dirt and wax were removed from the orifices. The first few streams were discarded and then about 10-15 milliliter of the milk samples from all quarters was collected in sterile test tube in an oblique manner to avoid contamination. Then the samples were transported to the laboratory for detailed microbiological analysis and the collected milk samples were examined fresh. Samples which were not processed immediately were put in refrigerator at $4^{0} \mathrm{c}$ for subsequent analysis within 12-24 hours.

\subsubsection{Microbiological Procedures}

All positive milk samples in CMT (California Mastitis Test) were analyzed microbiologically. Samples from individual quarter were centrifuged at $2500 \mathrm{rpm}$ (revolution per minute) for 5 minutes and the supernatant discarded. Standard loop full milk was removed from the sediment and cultured on blood agar plates containing sheep blood, Mac Conkey Agar plates and Edward's Agar plates, and incubated at $37^{\circ} \mathrm{c}$ for $18-24$ hours. The plates were then examined for growth of micro-organisms and those negatives were re-incubated further up to 4 days, after which the conclusion of no growth of micro-organisms was arrived at. (Quinn et al., 2002)

Identification of bacterial isolates was made on the basis of morphology, color and size of colonies, presence or absence of haemolysis production, and Gram stain. The identification of bacterial isolates to the species level was made by sub-culturing a single pure colony and conducting different biochemical tests. Therefore, the targeted organisms during culture were mainly; Staphylococcus species, Streptococcus species, Escherichia coli, Corynebacterium species and Salmonella. The details on the procedure are described by (Chakraborty, 2005).

Staphylococcus species were identified and differentiated by Gram staining, colony morphology, oxidase test, ability to produce haemolysin, ability to ferment maltose, catalase test and slide coagulase test. Streptococcus species were identified and differentiated by colony morphology, catalase test, and growth characteristics on Edward's medium to produce haemolysin, oxidase test and CAMP test. Coli form species were identified and differentiated by colony morphology on Macconkey agar, Gram stain, motility test, indole test, and Triple sugar iron agar test to detect sugar fermentation. Corynebacterium species were identified and differentiated by colony morphology, Gram stain, haemolysin production, catalase test, Indole test and fermentation on glucose and manitol. Salmonella are identified and differentiated by growth on ordinary culture media, indole test, and fermentation on lactose, glucose and maltose.(Chakraborty, 2005). 
A Study on the Prevalence of Bovine Mastitis and Isolation of Major Pathogens Associated with it in and around Wolaita Sodo, Southern Ethiopia

\subsubsection{Data Management and Analysis}

All the data collected on the sample collection format and from the microbiology culture and biochemical tests were recorded and coded on excel spreadsheet. Statistical analysis was done using STATA $^{\circledR}$ version 11 . The prevalence of clinical and subclinical mastitis was calculated using percentage values, and the possible association of the disease with different risk factors like breeds, stage of lactation, parity and origin were analyzed using chi-square $\left(\chi^{2}\right)$ test. Californian Mastitis Test (CMT) was used for sub-clinical mastitis prevalence and physical examination and bacterial culture method for clinical and sub-clinical mastitis cases. The prevalence of blind/ blocked quarters was also included in the study.

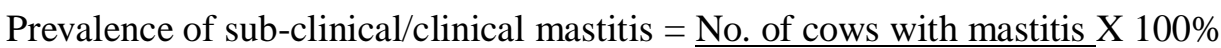

Total No. of lactating cows examined

Quarter prevalence $=\quad$ No. of positive quarters X 100\%

Total No. of quarters screened

Prevalence of blind/blocked quarters = No. of quarters blind/blocked X $100 \%$

Total No. of quarters examined

\section{RESUltS}

\subsection{Overall Seroprevalence}

A total of 349 dairy lactating cows were examined for the presence of mastitis infection both clinically and sub clinically. The prevalence was calculated at cow and quarter level. The overall mastitis prevalence at cow level was 35.5\% (124/349), out of which 5.4\% (19/349) and 30.1\% $(105 / 349)$ were clinical and sub clinical infections, respectively. The quarter level prevalence was $25.7 \%$ (359/1396); from this the clinical form was 4.4\% (62/1396) and the sub clinical was $21.3 \%$ (297/1396) and it is indicated in Table 1. In this study, the overall prevalence of the blind quarter was $3.8 \%$ (53/1396). And62 quarters with clinical cases revealed active cases of mastitis showing visible signs of inflammation on the udder and changes were observed on the milk.

Table1. Summary of CMT score $(n=1396)$ and culture result of mastitic cows at quarter level

\begin{tabular}{|l|l|l|l|l|}
\hline \multirow{2}{*}{ Forms of mastitis } & \multicolumn{2}{|c|}{ CMT } & \multicolumn{2}{c|}{ Culture } \\
\cline { 2 - 5 } & No. of positive & \% positive & No. of culture & \% positive \\
\hline Clinical & 62 & 4.4 & 62 & $62(100.0)$ \\
\hline Sub clinical & 297 & 21.3 & 297 & $287(96.6)$ \\
\hline Total & 359 & 25.7 & 359 & $349(97.2)$ \\
\hline
\end{tabular}

Table2. Prevalence of mastitis with respect to origin as urban and per urban

\begin{tabular}{|l|c|c|c|}
\hline \multirow{2}{*}{ Mastitis } & Urban & Peri-urban & Total \\
\cline { 2 - 4 } & No. of positives (\%) & No. of positives (\%) & No. of positives (\%) \\
\hline Not affected & $131(66.2)$ & $94(62.3)$ & $225(64.3)$ \\
\hline Affected & $67(33.8)$ & $57(37.7)$ & $124(35.7)$ \\
\hline Total & $198(100.0)$ & $151(100.0)$ & $349(100.0)$ \\
\hline
\end{tabular}

*The numbers inside the bracket indicate percentage Pearson $\chi^{2}(1)=0.572, p>0.05$

Table3. Prevalence of mastitis by breed

\begin{tabular}{|l|l|l|l|l|}
\hline Mastitis & Jersey & Holstein & Zebu & Total \\
\hline Not affected & $44(72.1)$ & $30(58.8)$ & $151(63.7)$ & $225(64.9)$ \\
\hline Affected & $17(27.9)$ & $21(41.2)$ & $86(36.3)$ & $124(35.1)$ \\
\hline Total & $61(100.0)$ & $51(100.0)$ & $237(100.0)$ & $349(100.0)$ \\
\hline
\end{tabular}

* The numbers inside the bracket indicate percentage Pearson $\chi^{2}(2)=2.332, p>0.05$

Table4. Prevalence of mastitis with respect to age groups

\begin{tabular}{|l|l|l|l|l|}
\hline Mastitis & Young & Adult & Old & Total \\
\hline Not affected & $48(62.3)$ & $77(67.5)$ & $100(63.3)$ & $225(64.4)$ \\
\hline Affected & $29(37.7)$ & $37(32.5)$ & $58(36.7)$ & $124(35.6)$ \\
\hline Total & $77(100.0)$ & $114(100.0)$ & $158(100.0)$ & $349(100.0)$ \\
\hline
\end{tabular}

* The numbers inside the bracket indicate percentage Pearson $\chi^{2}(6)=0.72 p>0.05$

International Journal of Research Studies in Biosciences (IJRSB) 
A Study on the Prevalence of Bovine Mastitis and Isolation of Major Pathogens Associated with it in and around Wolaita Sodo, Southern Ethiopia

Table5. Prevalence of mastitis with respect to parity

\begin{tabular}{|l|l|l|l|l|}
\hline Mastitis & Few(1-2) & Moderate(3 or 4) & Many(>5) & Total \\
\hline Not affected & $110(67.5)$ & $115(67.7)$ & $0(0.00)$ & $225(44.4)$ \\
\hline Affected & $53(32.5)$ & $60(34.3)$ & $11(100)$ & $124(55.6)$ \\
\hline Total & $163(100.0)$ & $175(100.0)$ & $11(100.0)$ & $349(100.0)$ \\
\hline
\end{tabular}

* The numbers inside the bracket indicate percentage Pearson $\chi^{2}(2)=20.72 p=0.000$

Table6. Prevalence of mastitis with respect to lactation stage

\begin{tabular}{|l|l|l|l|l|}
\hline Mastitis & Early(1-4months) & Medium (4-8months) & Late(>8months) & Total \\
\hline Not affected & $59(69.4)$ & $71(62.8)$ & $95(62.9)$ & $225(65)$ \\
\hline Affected & $26(30.6)$ & $42(37.2)$ & $56(37.1)$ & $124(35)$ \\
\hline Total & $85(100.0)$ & $113(100.0)$ & $151(100.0)$ & $349(100.0)$ \\
\hline
\end{tabular}

* The numbers inside the bracket indicate percentage Pearson chi $^{2}(2)=1.2 p>0$

Table7. Relative isolation rate of mastitis associated organisms out of total 113 isolates

\begin{tabular}{|l|c|c|}
\hline Bacteria isolated & No. of isolates & Rate of isolation \\
\hline E. coli & 3 & 2.7 \\
\hline Coryne. bovis & 2 & 1.8 \\
\hline Salmonella & 2 & 1.8 \\
\hline Staph. aurues & 61 & 53.9 \\
\hline Strep. aysagalactiae & 4 & 3.5 \\
\hline Strep. agalactiae & 41 & 36.3 \\
\hline Total & 113 & 100.0 \\
\hline
\end{tabular}

The milk samples collected from 297 CMT - positive sub clinical cases and 62 clinical mastitis cases were cultured. Accordingly, 287 (96.6\%) of the 297 sub-clinical cases and all the 62 clinical cases were culture positive. Therefore, out of 359 cultures, growths were observed on 349(97.2\%). From this 349 growth, 113 bacteria of 5 genera were isolated. The most prevalent mastitis causing pathogen in the current study was Staphylococcus; of which the predominant species were hemolytic coagulase positive $S$. aurues, representing 53.9\%. Other bacterial isolates were Streptococcus species (39.8\%), E. coli (2.7\%), Corynebacterium species (1.8\%) and, Salmonella (1.7\%) with decreasing order of frequency.

The relative isolation rate of mastitis associated organisms from milk sample cultured from clinical and subclinical infections is indicated in Table 7. The genus Staphylococcus was the predominantly isolated organism. This was followed by Streptococcus species, E. coli, Corynebacterium species and Salmonella.

\section{DISCUSSION}

The study carried out to determine the prevalence of bovine mastitis in and around Wolaita Sodo town revealed that $35.5 \%$ of animals examined showed the evidence of mastitis. Out of which $5.4 \%$ and $30.1 \%$ were clinical and sub clinical, respectively. Sub clinical mastitis has been reported to be higher than clinical mastitis, owing to the defense mechanisms of the udder; which reduces the severity of the disease (Erskine, 2001). The overall prevalence of mastitis in the current study showed the presence of many sub clinical cases (carrier), lack of herd health monitoring and empirical treatment of cases and deficiency of existing management. The finding of this study is in line with the previous reports by Dersema (1991) and Biffa et al. (2005) who respectively reported 36.9\% and 34.9\% prevalence of mastitis in southern Ethiopia, in selected areas of Wolaita Sodo. On the other hand, it was found higher than the report of Nessru et al. (1997), who reported a prevalence of 25\%. The finding of this study was found lower than the previous reports by Mekibib et al. (2010), who reported $71 \%$ prevalence of mastitis in dairy farms of Holeta town, central Ethiopia.

Overall quarter prevalence of $25.7 \%$ was recorded in the current study, which is comparable with the $28.2 \%$ reports of Biffa et al. (2005) in the same area. On the other hand, Nessru et al. (1997) reported higher than the current study. But Almaw (2004) reported lower quarter prevalence (17.9\%) than the current one. The $8.2 \%$ quarter prevalence of clinical mastitis agrees with the fact indicated by Radostits (1994) for bovine clinical mastitis (10\%); and it is also in line with the report of Biffa et al. (2005) (12.2\%). On the other hand, it was lower than the report of Workneh et al. (2002), who found a prevalence of $21.5 \%$ for clinical mastitis in Debrezeit area. 
From the 297 CMT-positive quarter milk samples, 3.4\% (10/297) were bacteria negative, which were lower than the reports of Mekibib et al. (2010), who reported the prevalence of mastitis in dairy farm of Holeta town. The failure to isolate bacteria from the CMT- positive milk samples could be partly associated with spontaneous elimination of infection, low concentration of pathogen in the milk, intermittent shedding of pathogen, and intracellular location of pathogens and presence of inhibitory substance in the milk (Radostits, 2000).

In this study, most of the bacterial pathogens isolated from milk sample were Staphylococcus species, S. aurues (53.9\%) being the predominant. In line with this finding, Biffa (1994) (51.14\%). The high prevalence of this organism may be associated with its frequent colonization of teats, its ability to exist intracellular and colonize within micro abscesses in the udder and hence resistant to antibiotic treatment (MacDonald, 1997). The bacteria usually establish chronic, sub clinical infections and are shed in the milk, which serves as a source of infection for other healthy cows during the milking process. Transmission among cows' increases whenever there is lack of effective udder washing and drying and disinfection, washing clothes and milking machine cups (Radostits, 1994).

Streptococcus species identified in the present study (39.8\% was higher than reported by Zerihun (1996) (27\%). This higher report of isolates in the current study might be partly associated with less use of penicillin in the area, which is known to be less effective to eradicate mastitis caused by Streptococcus species (Soriet al., 2002), the present study also identified also a low prevalence of $E$. coil $(2.7 \%)$, Corynebacterium bovis (1.8\%) and Salmonella (1.8\%). Corynebacterium species accounted for $1.8 \%$ of a total isolates. This figure was found lower than the report work of Geressu (1989) (4.2\%) and Mengistu (1989) (3.64\%).

The lower isolation rate of coliform organisms $(2.7 \%)$, despite their wide spread distribution in the environment of the dairy cows may be attributed to the fact that their multiplication is restricted and thus may become unable to establish themselves in a gland, as long as the more common mastitis pathogens (Gram positive cocci) are available to invade mammary gland and stimulate a leukocytes in milk (Schalmet al., 1971). Their lower isolation rate may also be attributed to their poor contagious nature (Eberhart, 1977).

The finding of the study was also assessed for breed predisposition to mastitis but no significant difference in the prevalence was detected among three breeds. Generally the prevalence of mastitis is greater in Holstein than in Jersey but this may reflect differences in management and udder conformation rather than true genetic differences. Valid comparison among breeds has not been reported (Radostitset al., 2007).

The increased prevalence of mastitis has significant difference with the parity groups in the current study. The increased prevalence of mastitis with parity reported in the present study is in agreement with the report of Biffa et al. (2005), who indicated an increase in prevalence. The age - multiparious - high prevalence relationship is explored to be due to an increase in teat patency and degree and frequency of previous exposure in multiparious old cow (Harmon 1994; Radostits (1994).

The occurrence of mastitis induced by blind mammary quarter (3.8\%), which has a paramount and direct impact on the dairy economy at least by reducing the amount of milk produced, signifies the importance of the problem. Lack of screening tests and treatment of sub clinical mastitis and in adequate follow up of clinical and chronic cases were believed to be the major reasons for the development of quarter's blindness. Though induced by persistent challenges of the mammary glands by microbial pathogens, it remains hidden and results in gradual destruction of the mammary tissues that ultimately causes non-functional quarters (Biffa, 2005).

\section{CONCLUSiOnS}

A study conducted from November 2011 to April 2012 at Sodo Regional Laboratory on Indigenous Zebu Jersey and high grade Holstein Friesian breeds in and around Wolaita Sodo town revealed a high prevalence of clinical and sub clinical mastitis implying significant economic loss. Moreover, most of the infections were sub clinical and the majority did not receive treatment. As a result, most of the infections act as a source of infection for other cows in the herd. Farmers and health managers only concerned with clinical mastitis and often are unaware of the prevalence of infection in their herds and resulting economic loss. The factors accounting for the high prevalence of the disease in the 
study area of southern Ethiopia comprises a complex relationship of host, agent and environment, of which the most exacerbating ones could be poor hygiene of the barns, unhygienic milking practice, lack of regular veterinarians checkups and supervision, lack of use of post milking teats dips in the dairy farms, lack of use of dry period therapy, negligence of culling animals with chronic mastitis most of which had more than one blind quarters and absence of treatment of clinical mastitis with practically effective drugs.

Control of mastitis in dairy herd can be accomplished in part with the aid of antibiotics. However, antibiotic treatment is not the entire answer to the mastitis problem. Moreover, indiscriminate use of drugs especially oxytetracycline which was widely used all over the area may have potential effect on the complexity of the development of resistant strain of bacteria. Due to the complexity of the problem of mastitis in these areas, the application of single preventive and control measure is impractical.

\section{REFERENCES}

Almaw, G. (2004): Cross sectional study of bovine mastitis in and around Bahirdar and antibiotic resistance patterns on major pathogens. MSc thesis, Addis Ababa University, Faculty of Veterinary medicine, Ethiopia.Pp.79.

Aregaw, M. (1992): Incidence of Mastitis and its Influence on Milk Yield and Composition in Debrezeit, DVMthesis, and AddisAbabaUniversity, Ethiopia, Pp71-78.

Biffa, D. (1994): The Study on the Prevalence of Bovine Mastitis in Indigenous Zebu Cattle and Jersey Breeds in WollaitaSodo, Characterization and in vitro Drug Sensitivity of the Isolates. DVM thesis, Addis Ababa University, Faculty of Veterinary medicine, Ethiopia. Pp. 71-78.

Biffa, D. Debela, E. and Beyene, F. (2005): Prevalence and Risk factors of mastitis in lactating drycowsinsouthernEthiopia.Inter.J.Appl.Res.Vet.Med.3 (3):189-198.

Biru, G. (1989): Major bacteria causing bovine mastitis and their sensitivity to common antibiotics. Eth.J.Agri.Sci. 11:4-6.

Bishi, A. S. (1998): Cross Sectional Study and Longitudinal Prospective Study of Bovine Clinical and Subclinical Mastitis in Per-urban and Urban Dairy Production System in Addis Ababa Region, Ethiopia (MSc Thesis, Addis Ababa University and Free University of Berlin, Germany).

Chakraborty P. (2005). Identification of bacteria. In: A text book of microbiology. New Central Book Agency (p) Ltd. India. Pp 231-337.

Eberhart B. J. (1977). Coli form mastitis. Colloquium on bovine mastitis. Journal of Animal. Vet. Med. Ass. Vol. 170.

Erskine, R.J. (2001). Food animal production medicine, $3^{\text {rd }}$ edition, W.B. Sounders Company, Pp 397-435.

Faull W.B. and Hughe J.W. (1995). Notes for dairy practitioners. Liver pool university press. Liver pool, UK. Pp 4-7.

Geressu B. (1989). Major bacteria causing mastitis and their sensitivity to common antibiotics. Ethiopia Journal of Agri. Sci. Vol. 11. No.2

Harmon R.J. (1994). Symposium: Mastitis and genetic evaluation of somatic cell count. J. Dairy Sci. 77:21032112.

Hillertton J.E (1996). In: Progress in dairy science. Walling ford, oxford shire, UK: AB international.P 171.

Hundera, S., Ademe, Z. Sintayeh, A. (2005).Dairy cattle mastitis in and around Sabata, Ethiopia. International journal for applied research of veterinary medicine, 3:332-338.

Kerro O. and Tareke F. (2003).Bovine mastitis in selected areas of Southern Ethiopia.Journal of Tropical Animal Health and Production. 35: Pp 196-205.

Lescouret F., Hill T.M. and Batmen H.G. (1993). Comparison of housing, bedding and cooling options for dairy cows. J Dairy Sci. 18:2167.

MacDonald, U.S. (1997): Streptococcal and Staphylococcal mastitis. J. Am. Vet. med. Assoc. 170:1157.

Mekibib, B., Furgasa, M., Abunna, F., Megersa, B. and Regassa, A. (2010): Bovine mastitis: Prevalence, risk factors and major pathogens in dairy farms of Holeta town. Faculty of veterinary medicine, Hawassa University.Vol.3(9): 397-403.

Mengistu M. (1986). Prevalence and an etiology of bovine mastitis in Bahir Dar.DVM thesis. Faculty of veterinary medicine, Addis Ababa University.

Nessru, H. Teshome, Y. and Getachew, T. (1997): Prevalence of mastitis in cross-bred 
Pyorola S. (2003). Indicates of inflammation in the diagnosis of mastitis. Vet. Res. 34:565-576.

Quinn P.J., Carter, M. E., Markey B. K. and Carter, G.R. (2002): Clinical veterinary microbiology. Harcourt publishers, Virginia.Pp 331-344.

Radostits, O.M. (1994): Herd health: Food animal production medicine, 2nd ed. W.B. Saunders Company, USA.Pp, 90-115.

Radostits, O.M. Gay, G. C. Blood, D. C. and Hinchillif, K. W. (2000): Veterinary Medicine, 9th Edition, HarcourtLimited, London, pp.603-700.

Radostits, O.M. Gay, G. C. Blood, D. C. and Hinchillif, K. W. (2007): Veterinary Medicine, 10th Edition, HarcourtLimited, London, Pp 673-762.

Risco C.A., Donoven G.A. and Hernandez J. (1999). Clinical mastitis associated with abortion in dairy cows. J Dairy Sci. 82: Pp 1684-1689.

Schalm DW, Carroll EJ, Jain C: Bovine Mastitis.Lea and Febiger: Philadelphia; 1971:20-158

Smith B.P. (1996). Large Animal Internal medicine: Disease of Horse, Cattle, Sheep and Goats, 2nd edition, Mos by year book USA, PP 1177-1188.

Smith K.L. and Hogan J.S. (1993).Environmental mastitis. In: Hunt, E.: Vet. Clinic. North America Food Animal Pract, update on bovine mastitis. W.B. Saunders Company, Philadelphia. Pp 489-518.

Smith K.L., conard H.R., Ameit B.A., Shoeberger P.S. and Tondhuten W.B. (1985).Effect of vitamin E and selenium supplementation on incidence of clinical and duration of clinical symptoms.J Dairy. Sci. 67: P 1295.

Sori, H. Zerihun, A. and Abdicho, S. (2005): Dairy Cattle Mastitis In and Around Sebeta, Ethiopia. Inter. J.Appl.Res.Vet.Med.3:332-38.

Steele M.L., McNab W.B., Poope C., Griffiths M. W., Chen S. and Degrandis S.A. (1997).Survey of Ontario bulk tank milk for food borne pathogens. J Food prot. 60: Pp 1341-1346.

Thrusfield, M. (2005): Veterinary epidemiology. $3^{\text {rd }}$ edition.Blackwell science, P 245.

Tolle A. (1984). Mastitis and veterinary preventive medicine, Proveterin Arians.

Wrkineh, S. Bayleyegn, M. Mekonnen, H. and Potgieter, L.N.D. (2003): Prevalence and etiology of mastitis in cows from two major Ethiopian dairies. TroAnim Health Prod. 34:19-25.

Zerihen T. (1996). A study on bovine sub clinical mastitis at Stela dairy farm, Ethiopia.DVM thesis, Addis Ababa University, Faculty of veterinary medicine, Ethiopia.Pp 45-52.

Citation: Esayas Balcha Madalcho., "A Study on the Prevalence of Bovine Mastitis and Isolation of Major Pathogens Associated with it in and around Wolaita Sodo, Southern Ethiopia", International Journal Of Research Studies In Biosciences (Ijrsb), Vol. 7, NO. 2, PP. 32-39, 2019. http://Dx.Doi.org/10.20431/23490365.0702004

Copyright: (C) 2019 Authors. This is an open-access article distributed under the terms of the Creative Commons Attribution License, which permits unrestricted use, distribution, and reproduction in any medium, provided the original author and source are credited. 